\title{
The Prevalence of Potentially Inappropriate Prescribing in Geriatric Patients with Psychiatric Disorders in Iraq Mustafa K. Mahmood ${ }^{*}, 1$ and Zinah M. Anwer*
}

*Department of Clinical Pharmacy, College of Pharmacy, University of Baghdad, Baghdad, Iraq.

\begin{abstract}
Potentially inappropriate prescribing is the prescribing of a medication that may cause more harm than benefit. The elderly population aged 65 years or older is more prone to potentially inappropriate prescribing because of the alterations in their physiology, pharmacokinetics, and pharmacodynamics as well as polypharmacy and comorbidities. Beers list is a screening tool that helps doctors to detect potentially inappropriate prescribing in geriatric patients and is designed to solve this problem. The aim of this study was to measure the prevalence of potentially inappropriate prescribing among psychiatric geriatric patients using the Beers criteria as an assessment tool and to find the relationship between PIP and the duration of hospitalization, comorbidities, and polypharmacy in elderly.

This cross-sectional study was carried out using electronic medical records in Ibn Rushd psychiatry and addiction hospital in Baghdad and 369 patients were included. The mean age of the patients was $(68.59 \pm 3.75$ years $)$ and $177(48 \%)$ of them had comorbidities, $100(27.1 \%)$ of them had polypharmacy and $17(4.6 \%)$ stayed in the hospital for more than 3 weeks, the most used drug classes were antipsychotics in $(39.9 \%)$ of patients and benzodiazepines in $(17.6 \%)$ of patients.

The prevalence of potentially inappropriate prescribing according to Beers criteria was found to be $74.3 \%$ among study patients, the most prevalent inappropriately used drug class was benzodiazepines, and there was a significant association between the prescribing of a potentially inappropriate medication with gender $(p=0.018)$, with comorbidities $(\mathrm{p}=0.022)$, and a very significant association with polypharmacy $(\mathrm{p}<0.001)$
\end{abstract}

Keywords: Potentially inappropriate prescribing, Potentially inappropriate medication, Beers criteria, Geriatric patients.

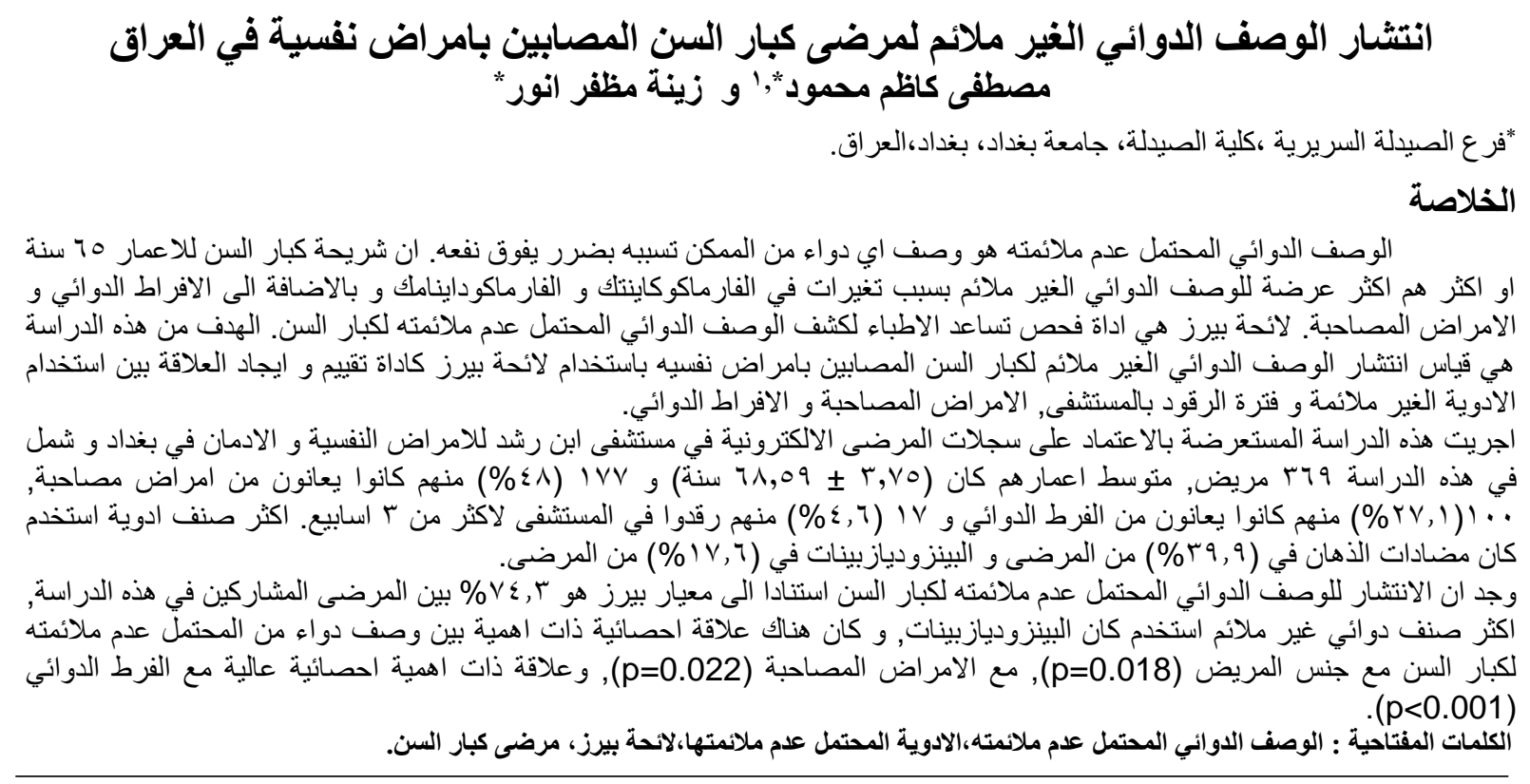

${ }^{1}$ Corresponding author E-mail: mustafa.kazum@gmail.com

Received: 26/ 8/2019

Accepted:7 /12 /2019

Iraqi Journal of Pharmaceutical Sciences 


\section{Introduction}

Potentially inappropriate prescribing (PIP) can be defined as the prescribing of a medication that the risk of adverse drug reaction may outweigh the benefit of the medication especially if there is a safer alternative available ${ }^{(1)}$.

The elderly population which is aged 65 years or older has been increasing rapidly, since the last century are very susceptible to the problem of PIP because of the alterations in their pharmacodynamics and pharmacokinetics as well as other drug-related problems such as polypharmacy and having multiple co-morbid diseases ${ }^{(2,3)}$.

There are many consequences of PIP, including increased adverse drug events such as cognitive impairment, falls and fractures which can lead to increase emergency room visits and prolonged hospitalization and increased health care use and cost ${ }^{(4-6)}$.

It is challenging to prescribe for geriatric patients with mental disorders because there are many factors influencing prescribing options that can cause alterations in pharmacokinetics such as changes in renal clearance, liver metabolic activity, brain volume, lean body mass and albumin binding this can lead to increased sensitivity to drugs effect especially in the central nervous system ${ }^{(7)}$. In addition, geriatrics with psychiatric disorders usually take several medications for the treatment of their mental disorders as well as other diseases, which increases the risk of drug-drug and drugdisease interactions. ${ }^{(8)}$

Patients with mental disorders may be less able to express their discomfort or drugrelated problems such as side effects especially in patients with dementia, therefore they may communicate their discomfort as aggression or agitation $^{(9)}$. This miscommunication may be perceived as worsening of their mental disease rather than a drug-related adverse effect. Lastly, the geriatric population are often excluded from most clinical trials, typically clinical trials conducted in adult population include patients between the ages of 18 and 64 years which causes a limited evidence base for medication use and safety in this population ${ }^{(10,11)}$.

This fact leads to the need of a screening tool that helps doctors to measure the appropriateness of the medications to be prescribed to the elderly and the first list for potentially inappropriate medications (PIMs) made was called the Beers criteria and was created in 1991 making it the longest-running criteria for detecting PIMs in the elderly, the criteria were revised and updated many times over the years and adopted by the American geriatric society, the criteria consist of five categories including drugs to be avoided regardless of condition and drugs to be avoided due to a certain disease/syndrome and drug interaction and drugs to be avoided due to drugdrug interaction ${ }^{(12)}$.

The aim of this study was to measure the prevalence of PIP among psychiatric geriatric patients using the Beers criteria as an assessment tool and to find the relationship between PIP and the duration of hospitalization, comorbidities, and polypharmacy in such patients.

\section{Patient and Methods Study design}

This cross-sectional observational study was carried out using the medical records of patients admitted to Ibn Rushd psychiatry and addiction hospital which is a large psychiatric teaching hospital in Baghdad, Iraq. The researcher retrospectively reviewed inpatient medical records over several years (from July 2011 to September 2018) and recorded any inappropriately prescribed cases.

\section{Inclusion criteria}

For this study, the inclusion criteria were:

1- Patient aged 65 years or older

2- Patient admitted for more than 24

hours

3- Patients received pharmacological therapy

4- Patients information was included in the hospital electronic medical record.

\section{Data collection}

The research reviewed medical records using a data collection sheet that was specifically designed by the research team to match study goals and it included the following information:

1- The age at the time of admission

2- Gender

3- Diagnosis

4- Administered medications

5- Length of stay

6- Comorbidities

\section{Screening tool}

To assess the appropriateness of prescribed medications the 2015 Beers list was used, the following table 1 shows a summary of the criteria used in this study for a medication to be considered inappropriate and was directly derived from the 2015 Beers criteria, these criteria were selected to measure the inappropriateness of psychotropic medications only. 
The most prescribed drugs were quetiapine (13.44\% of all prescribed drugs), procyclidine (9.3\%) and haloperidol (7.92\%).

Table 2. Patients characteristics and administered medication

\begin{tabular}{|l|l|}
\hline Age: mean (SD) years & $68.59(3.75)$ \\
\hline Females: n (\%) & $160(43.4 \%)$ \\
\hline Benzodiazepines: n (\%) & $239(17.6 \%)$ \\
\hline Antipsychotics: n (\%) & $550(39.9 \%)$ \\
\hline Antidepressant: n (\%) & $213(14.79 \%)$ \\
\hline $\begin{array}{l}\text { Antiepileptics as mood stabilizer: } \\
\text { n (\%) }\end{array}$ & $138(13.28 \%)$ \\
\hline Anticholinergics for EP*: n (\%) & $128(9.3 \%)$ \\
\hline $\left.\begin{array}{l}\text { other medications: n (\%) } \\
\hline \begin{array}{l}\text { Drugs prescribed per patient: } \\
\text { median, (IQR) }\end{array}\end{array}\right) 4,(2)$ \\
\hline Patients with comorbidities & $177(48 \%)$ \\
\hline $\begin{array}{l}\text { Patients prescribed with 5 drugs } \\
\text { or more: n (\%) }\end{array}$ & $100(27.1 \%)$ \\
\hline *Etrapyramidal side effect. \\
\hline
\end{tabular}

The duration of hospitalization in 216 patients $(58.5 \%)$ was less than one week, $136(36.9 \%)$ from one week to three weeks and $17(4.6 \%)$ stayed for more than three weeks.

Among the 369 patients, 177 patients (48\%) were complaining from comorbidities the most prevalent diseases were hypertension $(63.8 \%)$ and diabetes mellitus (35.6\%).

\section{Prevalence of PIP}

\section{PIMs regardless of patient condition}

In this study, the overall number of PIMs that were prescribed inappropriately regardless of patient condition was 323 . The most frequent inappropriately prescribed medications were: Diazepam (18.27\%), Quetiapine (16.72\%) and Alprazolam $(10.84 \%)$. The distribution of non-conditional PIMs is shown in table .

Table 3 . Potentially inappropriate medication regardless of patient condition

\begin{tabular}{|c|c|c|}
\hline Potentially inappropriate medication & No. & Percentage $(\%)$ \\
\hline Antidepressant & 49 & $15.17 \%$ \\
\hline Amitriptyline & 26 & $8.05 \%$ \\
\hline Clomipramine & 19 & $5.88 \%$ \\
\hline Imipramine & 2 & $0.62 \%$ \\
\hline Paroxetine & 2 & $0.62 \%$ \\
\hline Second generation antipsychotics & 86 & $26.63 \%$ \\
\hline Quetiapine & 54 & $16.72 \%$ \\
\hline Olanzapine & 21 & $6.50 \%$ \\
\hline Risperidone & 11 & $3.41 \%$ \\
\hline First generation antipsychotics & 27 & $8.36 \%$ \\
\hline haloperidol & 16 & $4.95 \%$ \\
\hline Flupenthixol & 6 & $1.86 \%$ \\
\hline Chlorpromazine & 3 & $0.93 \%$ \\
\hline Trifluoperazine & 1 & $0.31 \%$ \\
\hline Fluphenazine & 1 & $0.31 \%$ \\
\hline Benzodiazepine & 161 & $49.85 \%$ \\
\hline Diazepam & 59 & $18.27 \%$ \\
\hline Alprazolam & 35 & $10.84 \%$ \\
\hline Clonazepam & 30 & $9.29 \%$ \\
\hline Chlordiazepoxide & 24 & $7.43 \%$ \\
\hline Lorazepam & 13 & $4.02 \%$ \\
\hline Non-Benzodiazepine & 2 & $0.62 \%$ \\
\hline \multirow[t]{2}{*}{ Zolpidem } & 2 & $0.62 \%$ \\
\hline & 323 & $100.00 \%$ \\
\hline
\end{tabular}


PIPs due to drug-condition interaction

There was 71 PIMs prescribed to the study patients as follows: Benzodiazepines in patients with delirium $(30.99 \%)$ and Benzodiazepines in patients with dementia
(19.72\%), and antipsychotics in patients with dementia (19.72\%).

The most frequent class of medications present was benzodiazepines as recorded in $54.94 \%$.

Table 4 .Potentially inappropriate medication regarding patient condition

\begin{tabular}{|l|l|l|}
\hline Potentially inappropriate medication & No. & Percentage (\%) \\
\hline Syncope & $\mathbf{6}$ & $\mathbf{8 . 4 5 \%}$ \\
\hline Olanzapine & 6 & $8.45 \%$ \\
\hline Delirium & $\mathbf{2 8}$ & $\mathbf{3 9 . 4 4 \%}$ \\
\hline Benzodiazepine & 22 & $30.99 \%$ \\
\hline Antipsychotics & 5 & $7.04 \%$ \\
\hline Chlorpromazine & 1 & $1.41 \%$ \\
\hline Dementia & $\mathbf{2 8}$ & $\mathbf{3 9 . 4 4 \%}$ \\
\hline Benzodiazepine & 14 & $19.72 \%$ \\
\hline Antipsychotics & 14 & $19.72 \%$ \\
\hline Falls & $\mathbf{7}$ & $\mathbf{9 . 8 6 \%}$ \\
\hline Benzodiazepine & 3 & $4.23 \%$ \\
\hline Antipsychotics & 3 & $4.23 \%$ \\
\hline Anticonvulsant & 1 & $\mathbf{2 . 8 2 \%}$ \\
\hline Parkinson & $\mathbf{2}$ & $2.82 \%$ \\
\hline Antipsychotics & $\mathbf{7 1}$ & $\mathbf{1 0 0 . 0 0 \%}$ \\
\hline & $\mathbf{2}$ & \\
\hline
\end{tabular}

The PIMs due to drug-drug interaction

355 PIMs were found and this occurred most frequently by inappropriate prescriptions of benzodiazepines $(42.5 \%)$, followed by antidepressants and antipsychotics $(29.6 \%$, and $26.7 \%)$

Table 5 .Potentially inappropriate medication due to drug-drug interaction

\begin{tabular}{|l|l|l||}
\hline Potentially Inappropriate Medication & No. & Percentage (\%) \\
\hline Benzodiazepines & 151 & $42.54 \%$ \\
\hline Antidepressants & 105 & $29.58 \%$ \\
\hline Antipsychotics & 93 & $26.20 \%$ \\
\hline Anticholinergics & 6 & $1.69 \%$ \\
\hline & $\mathbf{3 5 5}$ & $\mathbf{1 0 0 . 0 0 \%}$ \\
\hline
\end{tabular}




\section{The total prevalence of PIP}

The prevalence inappropriate psychotropic medications was $74.3 \%$, while the remaining $25.7 \%$ received appropriately prescribing medications.

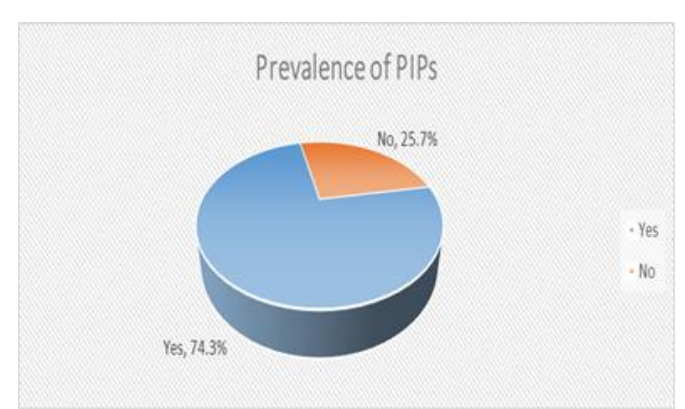

Figure 1 . Prevalence of potentially inappropriate prescribing in this study.
The association of PIPs with certain demographic data, comorbidities, and duration of hospitalization

The study revealed that $78.9 \%$ of male patients in this study received psychotropic medications inappropriately, with statistically significant association $(\mathrm{P}=0.018)$ between gender of patients and prescription of inappropriate psychotropic medications, this study also found a statistically significant association $(\mathrm{P}=0.022)$ between the presence of comorbidities and PIMs prescription, and there was a highly significant association between polypharmacy and being prescribed a potentially inappropriate medication $(\mathrm{P}<0.001)$.

Table 6. Association of PIPs with patient factors

\begin{tabular}{|c|c|c|c|c|}
\hline \multirow[b]{2}{*}{ Variable } & \multicolumn{2}{|l|}{ PIPs } & \multirow{2}{*}{$\begin{array}{l}\text { Total }(\%) \\
\mathrm{n}=369\end{array}$} & \multirow[b]{2}{*}{ P- Value } \\
\hline & $\begin{array}{l}\text { Yes }(\%) \\
n=274\end{array}$ & $\begin{array}{l}\text { No }(\%) \\
n=95\end{array}$ & & \\
\hline \multicolumn{5}{|l|}{ Age (Years) } \\
\hline$\leq 70$ & $213(74.5)$ & $73(25.5)$ & $286(77.5)$ & \multirow{2}{*}{0.857} \\
\hline$>70$ & $61(73.5)$ & $22(26.5)$ & $83(22.5)$ & \\
\hline \multicolumn{5}{|l|}{ Gender } \\
\hline Male & $165(78.9)$ & $44(21.1)$ & $209(56.6)$ & \multirow{2}{*}{ 0.018* } \\
\hline Female & $109(68.1)$ & $51(31.9)$ & $160(43.4)$ & \\
\hline \multicolumn{5}{|l|}{ Comorbidities } \\
\hline Yes & $141(79.7)$ & $36(20.3)$ & $177(48.0)$ & \multirow{2}{*}{$0.022 *$} \\
\hline No & $133(69.3)$ & $59(30.7)$ & $192(84.3)$ & \\
\hline \multicolumn{5}{|c|}{ Duration of Hospitalization (Weeks) } \\
\hline$<$ One & $155(71.8)$ & $61(28.2)$ & $216(58.5)$ & \multirow{3}{*}{0.331} \\
\hline One - Three & $107(78.8)$ & $29(21.3)$ & $136(36.9)$ & \\
\hline$>$ Three & $12(70.6)$ & $5(29.4)$ & $17(4.6)$ & \\
\hline \multicolumn{5}{|l|}{ polypharmacy } \\
\hline$\geq 5$ medications & $88(88)$ & $12(12)$ & $100(27.1)$ & \multirow{2}{*}{$0.0002 *$} \\
\hline$<5$ medications & $186(69.1)$ & $83(30.9)$ & $269(72.9)$ & \\
\hline
\end{tabular}

*Significant difference according to the chi-square test

\section{Discussion}

The results of the study shows that the antipsychotics were the most widely used medication by $(39.9 \%)$ of the total number of geriatric patient enrolled in this study but it wasn't the most frequent inappropriately prescribed medication due to the exception made by the criteria to geriatric patients diagnosed with schizophrenia, bipolar disorder or acute psychotic episodes that threaten to cause harm to self or others ${ }^{(12)}$.

There are several factor that lead to the high prevalence of PIPs in $74.3 \%$ of this study patients such as: most patients admitted due to acute psychological conditions or agitation which in turn required aggressive therapeutic plans to improve patient's condition, combined with the lack of safer alternative interventions which lead to the increased use of anxiolytics, hypnotics and antipsychotic injections; other factors that may have caused a false increase in PIPs is due to a flaw in the criteria itself for not providing a rule regarding a duration of medication use to be considered inappropriate which lead to many medications used only once 
by the patients to be counted as potentially inappropriate ${ }^{(13-16)}$.

However, the result of the present study is similar to (M Gutiérrez-Valencia et al., $2017)^{(14)}$ which measured a PIP prevalence of $71.5 \%$ in hospitalized geriatric patients in acute setting in Spain, and also similar to (G. Fond et al.,2016) ${ }^{(17)}$ which measured prevalence of PIP of psychotropic medications in hospital setting after discharge in France and found it to be $76.1 \%$, another study measuring PIPs in psychiatric hospital in the Netherlands (S. Rongen et al.,2016) ${ }^{(16)}$ found a much lower prevalence of $47 \%$.

The second major result of this study is that benzodiazepines was the most prevalent PIM used, this is also similar to other studies such as (M Gutiérrez-Valencia et al., 2017) ${ }^{(14)}$ in Spain which measured the impact of hospitalization on PIP and found Benzodiazepines as the most inappropriately prescribed medication, other studies concerning elderly patients treated with psychotropic medications in Spain such as (X. Vidal et al.,2016) ${ }^{(18)}$ found benzodiazepines as the most prescribed medications as well as the most inappropriately prescribed medication, as mentioned before this result is most likely due to the acute nature of most admissions.

It was interesting to notice the differences in prevalence of polypharmacy in geriatric patients among different studies concerning with the subject of potentially inappropriate prescribing ranging from as high as $95 \%$ in the study by (MF. Najjar et al,.2018) ${ }^{(13)}$ in Saudi Arabia, $86.5 \%$ in the study by (M Gutiérrez-Valencia et al., 2017) ${ }^{(14)}$ in Spain, $79 \%$ in the study by (S. Rongen et al.,2016) ${ }^{(16)}$ in the Netherlands to $29 \%$ In a study by $(\mathrm{H} \text {. Cho et al,.2018) })^{(15)}$ in South Korea despite being defined in all these studies as patients receiving 5 or more medications, it was also found to be a significant factor for the prescribing of an inappropriate medication in all of these studies similarly to the result of this study even though we found polypharmacy only in $27 \%$ of the study participants which can be explained by the methodology of this study which included only listing the medications in the electronic medical chart which doesn't include medications used for other diseases such as hypertension or diabetes.

Gender and age were considered to be a significant factor in the prescribing of PIM is some studies (G. fond et al.,2016) ${ }^{(17)}$ and $(\mathrm{H}$. Cho et al,.2018) $)^{(15)}$, and considered to be insignificant in others (X. Vidal et al.,2016) ${ }^{(18)}$, this can be explained by differences in study settings, prescribed medications, and discrepancies in other factors.

\section{Conclusions}

There is a high prevalence of potentially inappropriate prescribing among geriatric patients with psychiatric disorders in Iraq in addition the factors affecting potentially inappropriate prescribing were gender (male), having a comorbid disease and taking more than 5 medications and found to be strongly associated with being prescribed a potentially inappropriate medication.

\section{References}

1. O'mahony D, O'sullivan D, Byrne S, O'connor MN, Ryan C, Gallagher $\mathrm{P}$. STOPP/START criteria for potentially inappropriate prescribing in older people: Version 2. Age Ageing. 2015;44(2):213218.

2. Sera LC, McPherson ML. Pharmacokinetics and Pharmacodynamic Changes Associated with Aging and Implications for Drug Therapy. Clin Geriatr Med. 2012;28(2):273-286.

3. Nobili A, Garattini S, Mannucci PM. Multiple diseases and polypharmacy in the elderly: challenges for the internist of the third millennium. J comorbidity. 2011;1:28-44.

4. Montastruc F, Duguet C, Rousseau V, Bagheri H, Montastruc J-L. Potentially inappropriate medications and adverse drug reactions in the elderly: a study in a PharmacoVigilance database. Eur J Clin Pharmacol. 2014;70(9):1123-1127.

5. Wong J, Marr P, Kwan D, Meiyappan S, Adcock L. Identification of inappropriate medication use in elderly patients with frequent emergency department visits. Can Pharm J / Rev des Pharm du Canada. 2014;147(4):248-256.

6. Cahir C, Fahey T, Teeling M, Teljeur C, Feely J, Bennett K. Potentially inappropriate prescribing and cost outcomes for older people: a national population study. Br J Clin Pharmacol. 2010;69(5):543-552.

7. Corsonello A, Pedone C, Incalzi RA. Agerelated pharmacokinetic and pharmacodynamic changes and related risk of adverse drug reactions. Curr Med Chem. 2010;17(6):571-584.

8. Dolder CR, Mckinsey J. Antipsychotic Polypharmacy Among Patients Admitted to a Geriatric Psychiatry Unit. J Psychiatr 
Pract. 2011;17(5):368-374.

9. Ahmed AIA, Van Den Elsen GAH, Van Der Marck MA, Olde Rikkert MGM. Cannabinoids for pain in dementia: The good, the bad, and the ugly. J Am Geriatr Soc. 2014;62(5):1001-1002.

10. Herrera AP, Snipes SA, King DW, TorresVigil I, Goldberg DS, Weinberg AD. Disparate Inclusion of Older Adults in Clinical Trials: Priorities and Opportunities for Policy and Practice Change. Am J Public Health. 2010;100(Suppl 1):S105.

11. Shenoy P, Harugeri A. Elderly patients' participation in clinical trials. Perspect Clin Res. 2015;6(4):184.

12. Samuel MJ. American Geriatrics Society 2015 updated beers criteria for potentially inappropriate medication use in older adults. J Am Geriatr Soc. 2015;63(11):2227-2246.

13. Najjar MF, Sulaiman SAS, Al Jeraisy M, Balubaid H. The impact of a combined intervention program: An educational and clinical pharmacist's intervention to improve prescribing pattern in hospitalized geriatric patients at King Abdulaziz Medical City in Riyadh, Saudi Arabia. Ther Clin Risk Manag. 2018;14:557-564.

14. Gutiérrez-Valencia $M$, Izquierdo $M$, Malafarina $\mathrm{V}$, et al. Impact of hospitalization in an acute geriatric unit on polypharmacy and potentially

inappropriate prescriptions: A retrospective study. Geriatr Gerontol Int. 2017;17(12):2354-2360.

15. Cho H, Choi J, Kim YS, et al. Prevalence and predictors of potentially inappropriate prescribing of central nervous system and psychotropic drugs among elderly patients: A national population study in Korea. Arch Gerontol Geriatr. 2018;74(September 2016):1-8.

16. Rongen S, Kramers C, O'Mahony D, Feuth TB, Olde Rikkert MGM, Ahmed AIA. Potentially inappropriate prescribing in older patients admitted to psychiatric hospital. Int $\mathrm{J}$ Geriatr Psychiatry. 2016;31(2):137-145.

17. Fond G, Fajula C, Dassa D, Brunel L, Lançon C, Boyer L. Potentially inappropriate psychotropic prescription at discharge is associated with lower functioning in the elderly psychiatric inpatients. A cross-sectional study. Psychopharmacology

(Berl). 2016;233(13):2549-2558

18. Vidal $X$, Agustí A, Vallano A, et al. Elderly patients treated with psychotropic medicines admitted to hospital: associated characteristics and inappropriate use. Eur J Clin Pharmacol. 2016;72(6):755-764.

Baghdad Iraqi Journal Pharmaceutical Sciences by bijps is licensed under a Creative Commons Attribution 4.0 International License. Copyrights@ 2015 College of Pharmacy - University of Baghdad. 